\title{
SURFACE PROPERTIES OF A NANOCRYSTALLINE Fe-Ni-Nb-B ALLOY AFTER NEUTRON IRRADIATION
}

\author{
Milan Pavúk — Jozef Sitek — Katarína Sedlačková*
}

\begin{abstract}
The effect of neutron radiation on the surface properties of the nanocrystalline $\left(\mathrm{Fe}_{0.25} \mathrm{Ni}_{0.75}\right)_{81} \mathrm{Nb}_{7} \mathrm{~B}_{12}$ alloy was studied. Firstly, amorphous $\left(\mathrm{Fe}_{0.25} \mathrm{Ni}_{0.75}\right)_{81} \mathrm{Nb}_{7} \mathrm{~B}_{12}$ ribbon was brought by controlled annealing to the nanocrystalline state. After annealing, the samples of the nanocrystalline ribbon were irradiated in a nuclear reactor with neutron fluences of $1 \times 10^{16} \mathrm{~cm}^{-2}$ and $1 \times 10^{17} \mathrm{~cm}^{-2}$. By utilizing the magnetic force microscopy (MFM), topography and a magnetic domain structure were recorded at the surface of the ribbon-shaped samples before and after irradiation with neutrons. The results indicate that in terms of surface the nanocrystalline $\left(\mathrm{Fe}_{0.25} \mathrm{Ni}_{0.75}\right)_{81} \mathrm{Nb}_{7} \mathrm{~B}_{12}$ alloy is radiation-resistant up to a neutron fluence of $1 \times 10^{17} \mathrm{~cm}^{-2}$. The changes in topography observed for both irradiated samples are discussed.

K e y w o r d s: nanocrystalline materials, neutron radiation effects, magnetic force microscopy, MFM, surface topography
\end{abstract}

\section{INTRODUCTION}

For the amorphous Fe-Si-Nb-B-Cu alloy it was shown, that in certain cases radiation may have also a positive impact on the physical properties of a material. For example, the $\mathrm{Fe}_{73.5} \mathrm{Si}_{13.5} \mathrm{Nb}_{3} \mathrm{~B}_{9} \mathrm{Cu}_{1}$ ribbon annealed below the crystallization temperature shall regain after irradiation with neutrons the ductility, which it had in the as-quenched state [1]. An amorphous thin film of the same composition, in turn, exhibits smaller magnetic anisotropy and coercivity after irradiation with heavy ions [2]. Although the positive reports mentioned above consider only amorphous systems, they afford a good motivation for studying of radiation effects in nanocrystalline alloys. Understanding of the mechanism, how the structural changes induced in nanocrystalline systems by irradiation improve some physical property may allow us to design new structures exhibiting advantageous properties. In addition, the later studies show that amorphous alloys (potentially also nanocrystalline alloys) are already considered for some applications requiring radiation resistance $[3,4]$. This is given by their good soft magnetic properties.

The $\left(\mathrm{Fe}_{1-x} \mathrm{Ni}_{x}\right)_{81} \mathrm{Nb}_{7} \mathrm{~B}_{12}$ alloy system becomes attractive because of the change in the crystalline structure of nanograins from bcc to fcc [5-7]. This is due to the increase in the $\mathrm{Ni}$ content at the expense of the Fe content. In alloys with low $\mathrm{Ni}$ concentration $(x \leq 1 / 7)$, only nanograins with bcc crystalline structure are formed in the first stage of crystallization. At higher Ni concentrations $(1 / 4<x \leq 1 / 3)$, a structure with coexisting bcc and fcc crystalline grains is formed. The alloy with the same content of $\mathrm{Fe}$ and $\mathrm{Ni}(x=1 / 2)$ forms in the first stage of crystallization only the fcc-FeNi phase. The alloys with a substantial share of $\mathrm{Ni}(x>1 / 2)$ contain besides the ferromagnetic fcc-FeNi phase, also the paramagnetic fcc- $(\mathrm{FeNi}){ }_{23} \mathrm{~B}_{6}$ phase. Nanograins with an fcc lattice are not commonly seen in any class of the nanocrystalline alloys.

In this work, we studied the impact of a neutron radiation on the surface properties of the nanocrystalline $\left(\mathrm{Fe}_{0.25} \mathrm{Ni}_{0.75}\right)_{81} \mathrm{Nb}_{7} \mathrm{~B}_{12}$ alloy. Changes in topography and domain structure were observed by means of magnetic force microscopy (MFM).

\section{EXPERIMENTAL DETAILS}

The amorphous $\left(\mathrm{Fe}_{0.25} \mathrm{Ni}_{0.75}\right)_{81} \mathrm{Nb}_{7} \mathrm{~B}_{12}$ alloy was produced by the planar flow casting process in the form of a ribbon, $10 \mathrm{~mm}$ wide and $25 \mu \mathrm{m}$ thick. About $2.5 \mathrm{~cm}$ long cuttings were then taken from the ribbon. These were subsequently annealed in vacuum at a temperature of $550{ }^{\circ} \mathrm{C}$ for 1 hour. By this procedure, we prepared samples of the $\left(\mathrm{Fe}_{0.25} \mathrm{Ni}_{0.75}\right)_{81} \mathrm{Nb}_{7} \mathrm{~B}_{12}$ alloy with nanocrystalline microstructure. Two of the nanocrystalline samples were irradiated in the TRIGA Mark-II reactor in Vienna the first one with a neutron fluence of $1 \times 10^{16} \mathrm{~cm}^{-2}$ and a second with the neutron fluence of $1 \times 10^{17} \mathrm{~cm}^{-2}$.

The Dimension Edge ${ }^{\mathrm{TM}}$ (Veeco Instruments Inc., Santa Barbara, CA, USA) atomic force microscope (AFM) was used to study the surface properties of the samples. We focused only on the air (shiny) side of the ribbons. Each ribbon sample was rotated under the AFM in order to achieve the scanning direction perpendicular to the longitudinal ribbon axis, which corresponds to the production direction. Thus, all AFM/MFM images presented in this paper are oriented with their vertical sides parallel to the longitudinal ribbon axis. Our probe was a Si tip with $\mathrm{Co}$ and $\mathrm{Cr}$ coating. The tip has a nominal radius of $35 \mathrm{~nm}$. The maximum tip radius declared by the manufacturer (Bruker, Camarillo, CA, USA) is $50 \mathrm{~nm}$. The resolution of the images is $512 \times 512$ pixels (data points). When taking MFM images, the microscope was operated

\footnotetext{
* Institute of Nuclear and Physical Engineering, Slovak University of Technology in Bratislava, Ilkovičova 3 , 81219 Bratislava, Slovakia, milan.pavuk@stuba.sk
} 

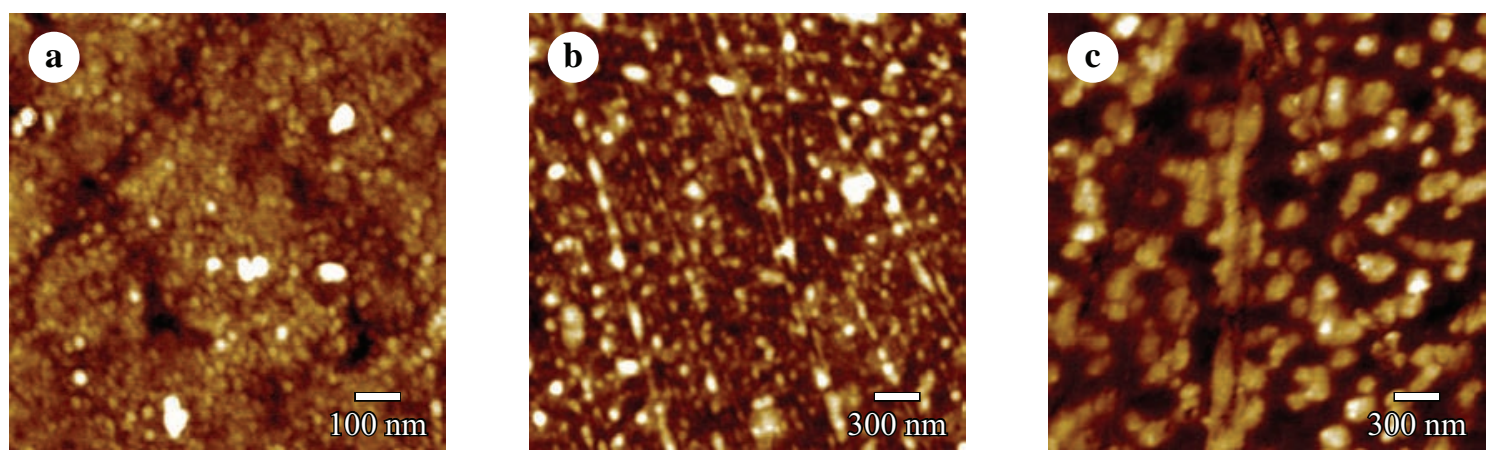

Fig. 1. Topography of the nanocrystalline $\left(\mathrm{Fe}_{0.25} \mathrm{Ni}_{0.75}\right)_{81} \mathrm{Nb}_{7} \mathrm{~B}_{12}$ alloy: Non-irradiated sample (a), sample irradiated with a neutron fluence of $1 \times 10^{16} \mathrm{~cm}^{-2}$ (b), sample irradiated with a neutron fluence of $1 \times 10^{17} \mathrm{~cm}^{-2}$ (c). The size of the scanned area is $1 \times 1 \mu \mathrm{m}^{2}$ and $3 \times 3 \mu \mathrm{m}^{2}$ for (a) and (b, c), respectively. Note: in AFM, lateral dimensions of surface objects are affected by tip-sample convolution and therefore, they seem to be wider than they really are
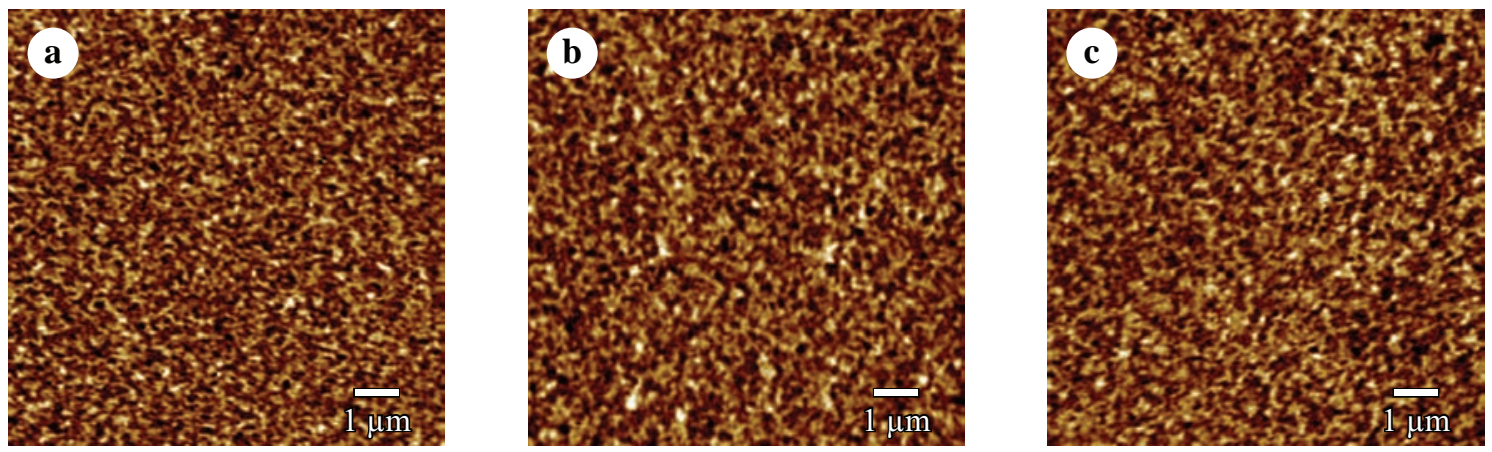

Fig. 2. Domain structure on the surface of the nanocrystalline $\left(\mathrm{Fe}_{0.25} \mathrm{Ni}_{0.75}\right)_{81} \mathrm{Nb}_{7} \mathrm{~B}_{12}$ ribbon: Non-irradiated sample (a), sample irradiated with a neutron fluence of $1 \times 10^{16} \mathrm{~cm}^{-2}$ (b), sample irradiated with a neutron fluence of $1 \times 10^{17} \mathrm{~cm}^{-2}$ (c). The size of the scanned area is $10 \times 10 \mu \mathrm{m}^{2}$. The images of the domain structure were recorded at a distance of $40 \mathrm{~nm}$ from the surface

in dynamic mode, ie recording a phase shift in resonant frequency of the cantilever oscillations, thus generating a map of magnetic domain structure of a sample. Topography was obtained in tapping mode as a part of the MFM scan.

The first measurements of the nanocrystalline $\left(\mathrm{Fe}_{0.25} \mathrm{Ni}_{0.75}\right)_{81} \mathrm{Nb}_{7} \mathrm{~B}_{12}$ alloy revealed that MFM signal of the irradiated specimens was basically at the detection limit of the microscope. It is important to realize that the MFM technique is sensitive only to the $z$-component of the stray magnetic field [8]. In order to enhance the MFM contrast, samples of the ribbon were magnetized before they were attached to the AFM sample holder. The probe magnetizer from the MFM tool kit (Veeco Instruments, Santa Barbara, CA, USA) was used for this purpose. The magnetic field was oriented perpendicular to the ribbon surface. This procedure enhanced the MFM contrast significantly. Mutual orientation of the magnet and the ribbon was preserved for all samples.

\section{RESULTS AND DISCUSSION}

Figure 1 shows the topography and Fig. 2 the domain structure of the nanocrystalline $\left(\mathrm{Fe}_{0.25} \mathrm{Ni}_{0.75}\right)_{81} \mathrm{Nb}_{7} \mathrm{~B}_{12}$ ribbon. The images were obtained by the atomic force microscope operating in MFM mode.
The surface of non-irradiated sample (Fig. 1a) is covered by very small protrusions. Their average height is around $1 \mathrm{~nm}$. The protrusions cover the entire scanned area. The equally high protrusions were also found in different locations on the surface. The first stage of structural transformation of this alloy is associated with formation of an extremely fine-grained crystalline fcc-FeNi phase [7]. Therefore, we assume that the observed protrusions are nanocrystalline grains $(\mathrm{FeNi})$. It is noteworthy that the alloy with this elemental composition retains a fine-grain structure also on the surface. The non-irradiated sample had a chaotic domain structure (Fig. 2a). According to Herzer [9], the random magnetocrystalline anisotropy of such small grains is suppressed by exchange interaction and the character of the domains is determined by residual anisotropies. Comparing the size of the recorded area shown in Fig. 2a and Fig. 1a, it can be seen, that the domains (b/w stripes in Fig. 2a) overlap a large number of grains.

The topography of the sample irradiated with a neutron fluence of $1 \times 10^{16} \mathrm{~cm}^{-2}$ is shown in Fig. 1b. Compared to the non-irradiated sample, the average height of protrusions increased to ca. $6 \mathrm{~nm}$.

$\left(\mathrm{Fe}_{0.25} \mathrm{Ni}_{0.75}\right)_{81} \mathrm{Nb}_{7} \mathrm{~B}_{12}$ sample was irradiated with the highest neutron fluence of $1 \times 10^{17} \mathrm{~cm}^{-2}$. In the topography, isolated protrusions are clearly visible (Fig. 1c). Their average height is about $14 \mathrm{~nm}$ (determined from 
the area of $\left.10 \times 10 \mu \mathrm{m}^{2}\right)$. After comparing numerous scans obtained from different regions of the surface, we found some differences in the average height of protrusions. It ranged from $12 \mathrm{~nm}$ to $19 \mathrm{~nm}$, depending on the location. Within smaller areas $\left(10 \times 10 \mu \mathrm{m}^{2}\right)$, the height of the individual protrusions did not change substantially.

From the topographic measurements of the nanocrystalline $\left(\mathrm{Fe}_{0.25} \mathrm{Ni}_{0.75}\right)_{81} \mathrm{Nb}_{7} \mathrm{~B}_{12}$ alloy we found out, that the average height of the protrusions on the sample surface grew with increasing neutron fluence. This suggests that during neutron irradiation, the temperature on the sample surface increased, and consequently the growth of already existing crystals was supported. Nevertheless, on the samples irradiated with neutron fluences of $1 \times 10^{16} \mathrm{~cm}^{-2}$ (Fig. 2a) and $1 \times 10^{17} \mathrm{~cm}^{-2}$ (Fig. 2b) we have not observed any qualitative change in their surface domain structure. Using power spectral density (PSD) analysis, we found that the domain structures in Fig. 2 do not have any preferential arrangement of domains.

\section{CONCLUSIONS}

Using MFM, we have studied the topography and domain structure of the as-prepared and neutron-irradiated nanocrystalline $\left(\mathrm{Fe}_{0.25} \mathrm{Ni}_{0.75}\right)_{81} \mathrm{Nb}_{7} \mathrm{~B}_{12}$ alloy. No significant changes found in domain structure of the irradiated samples of the nanocrystalline $\left(\mathrm{Fe}_{0.25} \mathrm{Ni}_{0.75}\right)_{81} \mathrm{Nb}_{7} \mathrm{~B}_{12}$ alloy indicates, that the alloy is well able to withstand neutron radiation up to a fluence of $1 \times 10^{17} \mathrm{~cm}^{-2}$. In terms of topography, changes in the size of protrusions were observed. The round protrusions, which may be ascribed to nanocrystalline grains, grew with increasing radiation fluence. Even in the most irradiated sample, the average height of protrusions did not, however, exceed $19 \mathrm{~nm}$. Based on this finding, we can conclude, that the sizes of the crystalline grains are still within the nanometre range (probably at the level of tens of nanometres). Accordingly, one of the conditions necessary for preservation of the favourable magnetic properties of the investigated alloy remained fulfilled.

\section{Acknowledgement}

The master ribbon was supplied by P. Švec from the Slovak Academy of Sciences in Bratislava. This work was supported by the Ministry of Education, Science, Research and Sport of the Slovak Republic via the project VEGA 1/0286/12 and co-financed by the EU from the project Centre of Competence in New Materials, Advanced Technologies and Energy, ITMS code 26240220073.

This paper summarizes in brief the essential issues of a work presented at APCOM-2014, International Conference on Applied Physics of Condensed Matter, held at Štrbske Pleso, High Tatras, Slovakia, on 25-27 June 2014.

\section{REFERENCES}

[1] ŠKORVÁNEK, I.-GERLING, R.-GRAF, T.-FRICKE, M. - HESSE, J.: Neutron Irradiation Effects on the Structural, Magnetic and Mechanical Properties of Amorphous and Nanocrystalline $\mathrm{Fe}_{73.5} \mathrm{Cu}_{1} \mathrm{Nb}_{3} \mathrm{Si}_{13.5} \mathrm{~B}_{9}$, IEEE Transactions on Magnetics 30 No. 2 (1994), 548-551.

[2] DUBEY, R.-GUPTA, A.-SHARMA, P.-DAROWSKI, N.SCHUMACHER, G.: Tailoring of Magnetic Anisotropy in Amorphous and Nanocrystalline Soft Magnetic Alloys using Swift Heavy Ions, Journal of Magnetism and Magnetic Materials 310 No. 2 (2007), 2491-2493.

[3] SPILLER, P.-BLASCHE, K.-FRANCZAK, B.-KIRK, M.HÜLSMANN, P.-OMET, C.-RATSCHOW, S.-STADLMANN, J. : Accelerator Plans at GSI for Plasma Physics Applications, Nuclear Instruments and Methods in Physics Research Section A: Accelerators, Spectrometers, Detectors and Associated Equipment 544 No. 1-2 (2005), 117-124.

[4] MIGLIERINI, M.-LANČOK, A.-PAVLOVIČ, M. : Ion Bombardment of Fe-based Amorphous Metallic Alloys, Hyperfine Interactions 189 No. 1-3 (2009), 45-52.

[5] TURČANOVÁ, J.-MARCIN, J.-KOVÁČ, J.-JANIČKOVIČ, D.-ŠVEC, P.- ¿ŠKORVÁNEK, I.: Magnetic and Mechanical Properties of Nanocrystalline Fe-Ni-Nb-B Alloys, Journal of Physics: Conference Series 144 No. 1 (2009), 012065.

[6] ŠVEC, P.-TURČANOVÁ, J.-JANIČKOVIČ, D.VÁNEK, I.- Š́VEC SR., P.: Interplanar Spacings of Complex Fe-Ni Phases in Rapidly Quenched Fe-Ni-Nb-B Systems, Journal of Physics: Conference Series 144 No. 1 (2009), 012092.

[7] ŠVEC, P.-MIGLIERINI, M.-DEKAN, J.-TURČANOVÁ, J.-VLASÁK, G.-ČKKORVÁNEK, I.-JANIČKOVIČ， D.ŠVEC SR., P.: Influence of Structure Evolution on Magnetic Properties of Fe-Ni-Nb-B System, IEEE Transactions on Magnetics 46 No. 2 (2010), 412-415.

[8] PERGOLINI, S.-VALDRÈ, G. : Nanocrystalline Cobalt Thin Films Observed by MFM and Lorentz Microscopy, Nanostructured Materials 9 No. 1-8 (1997), 627-630.

[9] HERZER, G.: Grain Structure and Magnetism of Nanocrystalline Ferromagnets, IEEE Transactions on Magnetics 25 No. 5 (1989), 3327-3329.

Received 15 July 2014

Milan Pavúk (Ing, PhD) born in 1980 in Bratislava, Slovakia, graduated from the Faculty of Electrical Engineering and Information Technology, Slovak University of Technology in Bratislava in branch Electromaterial Engineering and received the PhD degree in Physical Engineering in 2010. Since 2008, he has worked as a researcher at the Department of Nuclear Physics and Technology at his alma mater.

Jozef Sitek (Prof, Ing, DrSc), born in Zhorsk Ves, Slovakia, in 1944, graduated from the Faculty of Electrical Engineering, Slovak University of Technology, in 1966. He received his PhD degree in Applied Physics in 1974 and a DrSc degree in Physics of Condensed Matter in 1994. At present, he is Professor for Condensed Matter Physics at the Institute of Nuclear and Physical Engineering, Faculty of Electrical Engineering and Information Technology.

Katarína Sedlačková (Ing, PhD), born in 1977 in Piešt'any, Slovakia, received her Master degree in Material Science Engineering from the Slovak University of Technology in Bratislava, the Faculty of Electrical Engineering and Information Technology, in 2001. She holds a PhD degree in Physical Engineering from the same university. Currently, she is employed as an assistant at the Institute of Nuclear and Physical Engineering. 